\title{
Los diferentes modelos forales de la UCD en la descentralización de las provincias vasco-navarras (1977)
}

\section{The different foral models of the UCD in the devolution of the Basque-Navarre provinces (1977)}

\author{
JUAN JOSÉ ECHEVARRÍA PÉREZ-AGUA \\ Universidad Complutense de Madrid \\ juanjoseechevarria@hotmail.com
}

Resumen: En 1977, en las primeras elecciones democráticas de la Monarquía restaurada, la coalición Unión de Centro Democrático (UCD) solo se presentó en tres de las cuatro provincias vasco-navarras. Pese a ello, logró convertirse, en dicho ámbito, en la tercera fuerza electoral, tras el Partido Socialista de Euskadi-PSOE y el Partido Nacionalista Vasco (PNV).

La formación acudió con un planteamiento favorable a la descentralización territorial, aunque no clarificado en cuanto a su marco geográfico: provincial o regional. Pese a ello, la propuesta de la UCD era no solamente foralista sino que, además, en sus dos variantes, hundía sus raíces en la foralidad. Hasta tal punto que esta posibilitó la vía autonómica provincial en Navarra, como quería la UCD de ese territorio, y la regional en las provincias vascongadas, como pretendía la de Vizcaya, pero conformado el ente unitario de un modo igualitario entre las provincias constituyentes, como logró la de Álava.

Palabras clave: Fueros, descentralización, País Vasco, Navarra, Transición.

Abstract: In 1977, when the Union of the Democratic Centre (UCD) coalition took part in the first democratic elections for Spain's recently restored parliamentary Monarchy, the party ran candidates only in three of the four Basque-Navarre provinces. Even so, it managed - within this limited territorial scope - the third electoral force, just after the Socialist Party of Euskadi-PSOE, and the Basque Nationalist Party PNV.

UCD came with a favourable approach to devolution of political powers in the territory, although it did not define its geographical framework: on the province or on the region. Despite this, the UCD's proposal was respectful of the Fueros (ancient Charters), clearly connected to their medieval roots. As a result, this model made it possible to devolve the provincial autonomous route in Navarre, in accordance with the wishes of the UCD party. At the same time, the regional route in the Basque provinces proposed by the UCD in

Recibido: 20 de enero de 2021; aceptado:25 de mayo de 2021; publicado: 30 de septiembre de 2021.

Revista Historia Autónoma, 19 (2021), pp. 185-201

e-ISSN: 2254-8726; https://doi.org/10.15366/rha2021.19.010 
Vizcaya was approved. But, in this last case, the model was adapted to the demand of the UCD achieved in Alava: a unitary entity where the three provinces have an equal power.

Keywords: Ancient Charters, devolution, Basque Country, Navarre, Transition.

\section{El acervo de la foralidad}

El presente artículo indaga en el acervo de la foralidad para analizar los posicionamientos políticos de la UCD en las distintas provincias vasco-navarras en 1977, año de las primeras elecciones democráticas tras la restauración monárquica.

La foralidad es mutable, habiendo variado sustancialmente en los seis siglos codificados de su existencia. De hecho, los fueros no son ni han sido nunca un cuerpo de normas fijas ${ }^{1}$. La mutabilidad foral es, pues, el elemento necesario para cualquier aproximación intelectual a la foralidad, condicionándola y permitiendo múltiples interpretaciones de la misma, extremo no desconocido en el período que se abrió con la muerte de Franco. Así, fueron constantes entonces las menciones a su actualización, pronunciadas por políticos reformistas, como los respectivos procuradores familiares en representación de Vizcaya, Martín Fernández Palacios ${ }^{2}$, y Guipúzcoa, Manuel María Escudero ${ }^{3}$, por políticos rupturistas, como el líder del Movimiento de Alcaldes, José Luis Elcoro ${ }^{4}$, e incluso por defensores del régimen, como el publicista del tradicionalismo y de la franquista diputación de Guipúzcoa, José Luis Banús, a través de las páginas de La Voz de España ${ }^{5}$, quien consideraba que esta debía ser mínima preservando el núcleo central de la misma $^{6}$. En sus diferentes consideraciones sobre los límites de la actualización foral, pesaban los planteamientos regionales, en los primeros, o provinciales, en el último.

También hubo entonces menciones a la actualización foral de instituciones que asumieron en los primeros momentos de la transición democrática un rol político, como la Real Sociedad Bascongada de los Amigos del País (RSBAP), que en su relevante declaración del 12 de mayo de 1976 abogó por "un régimen de libertad dentro de la comunidad nacional, que sea continuación

\footnotetext{
${ }^{1}$ Fernández Rodríguez, Tomás Ramón, Los derechos históricos de los territorios forales. Bases constitucionales y estatutarias de la Administración Foral Vasca, Madrid, Civitas, 1985, p. 45.

${ }^{2}$ Gandarias, M. J., "Martín Fernández Palacios", en La Gaceta del Norte, 29 de agosto de 1976, p. 7.

${ }^{3}$ Archivo Central del ministerio de la Presidencia [en adelante ACP], Fondo de la Secretaría General Técnica [en adelante FSGT], Caja 2273, pp. 434-554, "Breve resumen de algunos datos con informe que en relación con los problemas del País Vasco, eleva el procurador familiar por Guipúzcoa, Manuel María Escudero y Rueda" (San Sebastián, 22 de julio de 1975).

${ }^{4}$ Elcoro, José Luis, "La reintegración foral, vista desde 1976", en El Diario Vasco, 7 de septiembre de 1976, p. 9.

${ }^{5}$ Echevarría Pérez-Agua, Juan José, "Banús: un publicista del Tradicionalismo", en Almuiña, Celso, Ricardo Martín de la Guardia y José Vidal Pelaez López (dir.), Perfiles de periodistas contemporáneos, Madrid, Fragua, 2016, pp. 219-231.

${ }^{6}$ Banús, José Luis, “Las tres fases de nuestra historia foral”, en La Voz de España, 18 de julio de 1976, p. 19.
} 
del viejo sistema foral adaptado a la realidad actual"7. Y más tarde por los partidos políticos que reclamaban su cuota de protagonismo, incluida la UCD. En esta última formación, destacó en ese planteamiento, además del mencionado Fernández Palacios, quien acudió en las listas de la UCD de Vizcaya en los comicios de 1977, el que sería dirigente de la coalición en Navarra, Jaime Ignacio del Burgo e igualmente candidato al Senado en las elecciones, quien ya desde 1975 propuso una restauración foral en las provincias vascongadas, adecuándola a la realidad existente, y una profundización de la vía foral en su dimensión provincial para Navarra ${ }^{8}$. Por su parte, el PSE-PSOE y el PNV suscribieron en mayo de 1977 un compromiso autonómico regional, aunque "sin perjuicio de la personalidad de cada región [provincia] histórica, ni renuncia a los poderes políticos basados en la plena reintegración foral" ${ }^{\prime}$. Socialistas y jeltzales ${ }^{10}$ admitían así que no podían obviar el planteamiento provincial. En el caso de los primeros, pesaba la posición anti-integracionista en Euskadi, que defendía el considerado ideólogo del partido en Navarra, José Antonio Asiáin Ayala ${ }^{11}$.

La actualización foral era, pues, clave, en la medida en que permitía implantar el marco geográfico pretendido por los diferentes actores políticos. Pero así, también había sido en el último siglo, desde que los tradicionalistas habían asumido la foralidad como algo intrínseco a su ideario. Así lo hizo Eustaquio de Echave-Sustaeta, quien incidió en la vigencia del marco original provincial de los fueros ${ }^{12}$. Y más tarde, Víctor Pradera, quien sostenía que "no hay la menor semejanza entre las instituciones y organización tradicionales de Álava, Guipúzcoa, Navarra y Vizcaya"13. Tal planteamiento incidía en las identidades provinciales existentes y constatadas historiográficamente al menos desde el siglo XIX ${ }^{14}$.

En cambio, la actualización foral que permitiera alcanzar una autonomía regional fue obra de otra interpretación foralista, la constitucionalista. Y en ella participaron los intransigentes a toda reducción foral, con Fidel de Sagarmínaga a la cabeza y su fracasado Partido Fuerista de Unión Vascongada ${ }^{15}$, y también, con mayor éxito, el diputado liberal José de Orueta, el propagador del proceso autonómico de dimensión regional vasca engarzado en la foralidad, que plasmó en su obra Fueros y autonomía, publicada en 1934, el texto básico del proceso unitario

\footnotetext{
7 "Declaración de la Real Sociedad Bascongada de los Amigos del País", en El Diario Vasco, 15 de mayo de 1976, p. 10.

${ }^{8}$ Burgo, Jaime Ignacio del, "El Régimen Foral de Navarra y las demás singularidades administrativas de España" (Pamplona, 1975), archivo personal del autor, pp. 1-74.

${ }^{9}$ Urrutia, Txema, Alcaldes en lucha. El Grupo de Bergara en la Transición, 1975-1979, Tafalla (Navarra), Txalaparta, 2006, p. 270.

${ }^{10}$ Se conoce así a los militantes del PNV, partidarios del JEL (Jaungoikoa eta Legezarrak, Dios y Leyes Viejas).

${ }^{11}$ Bueno Urritzelki, Mikel, "Los inicios de un partido nuevo: la creación del PSOE en Navarra (1974-1976), en Revista Historia Autónoma, 17 (2020), p. 101. https://doi.org/10.15366/rha2020.17.005

${ }^{12}$ Arana Goiri, Sabino, Obras Completas, San Sebastián, Sendoa, 1980, p. 1118.

${ }^{13}$ Pradera, Víctor, El Estado Nuevo, Burgos, Editorial Española, 1937, p. 137.

${ }^{14}$ Rubio Pobes, Coro, La identidad vasca en el siglo XIX. Discurso y agentes sociales, Madrid, Biblioteca Nueva, 2003, p. 22.

${ }^{15}$ Luengo Teixidor, Félix, "Restauración, identidad, fueros y autonomía. Liberales, republicanos y carlistas en la construcción de la identidad vasca (1876-1923)", en Castells, Luis y Arturo Cajal (eds.), La autonomía vasca en la España contemporánea (1808-2008), Madrid, Marcial Pons, 2009, p. 140.
} 
$\operatorname{vasco}^{16}$. Tal concepción, que además se arrogaba la condición de ser la única evolución posible de la foralidad, como muestra la interpretación que hizo la RSBAP de la Liga Foral Autonomista de principios del novecientos ${ }^{17}$, llegó incólume a la transición democrática, haciéndola suya la práctica totalidad de los actores políticos presentes entonces, salvo las diputaciones, el único residuo franquista en aquellas provincias, con la intención de impedir la democratización, y, por el motivo contrario, la UCD de Navarra y de Álava. Evidentemente, dichos planteamientos constitucionalista y tradicionalista sobre la foralidad incidían en la diversa consideración del sujeto decisorio: un pueblo regional o provincial. Una tercera interpretación de la foralidad, la soberanista, fue hecha suya por el PNV a partir de $1906^{18}$, tras su primera asamblea ${ }^{19}$, una vez que los herederos de los intransigentes, los euskalerriacos, habían confluido en el partido ${ }^{20}$, incidiendo en el unitarismo vasco, en un marco obviamente regional.

\section{Las elecciones democráticas de 1977}

La UCD obtuvo en los comicios de 1977, un total de 204.636 votos al Congreso de los Diputados, en las tres provincias en las que se pudo presentar. El 16,74\% del censo y el 21,27\% de los votantes en Vizcaya, Álava, y Navarra. Y fue la formación más votada en estos dos últimos territorios: el 30,19\% de los votantes y el 25,04 \% del censo en la provincia meridional, uno de cada cuatro habitantes con derecho a voto, y el 28,58 \% y el 23,50 \% en el viejo reino, más de uno de cada cinco. En Vizcaya fue apoyada por el 15,93 \% de los votantes y el $12,17 \%$ del censo. Cerca de uno de cada ocho vizcaínos con derecho a voto respaldó a la $\mathrm{UCD}^{21}$.

Guipúzcoa evidenció el fiasco del exconsejero nacional por esa provincia Marcelino Oreja Aguirre, ministro de Asuntos Exteriores del gobierno Suárez, hijo del político tradicionalista asesinado en la Revolución de Octubre de 1934. Oreja había abierto en los veranos de 1976 y 1977 en San Sebastián como ministro de Jornada la interlocución con la oposición, entre

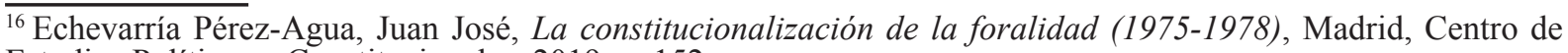
Estudios Políticos y Constitucionales, 2019, p. 152.

17 "Sociología electoral de Guipúzcoa (1900-1936) de Antonio Cillán Apalategui”, El Diario Vasco, 20 de febrero de 1976 , p. 8.

${ }^{18}$ Baraibar Etxeberria, Álvaro, “La LORAFNA en el contexto ideológico de la transición”, en Hermes, 25 (2008), p. 63. ${ }^{19}$ Artola, Miguel, Partidos y programas políticos (1808-1936). Manifiestos y programas políticos, Madrid, Aguilar, 1975, p. 239.

${ }^{20}$ Corcuera, Javier, "El nacionalismo vasco en la restauración. Purismo y posibilismo", en Castells, Luis y Arturo Cajal, La autonomía vasca en la España contemporánea (1808-2008), Madrid, Marcial Pons, 2009, pp. 189-193.

${ }_{21}$ Gobierno de España. Ministerio del Interior, Consulta de resultados electorales, Congreso junio 1977 (2014). «http://www.infoelectoral.interior.es/min/busquedaAvanzadaAction.

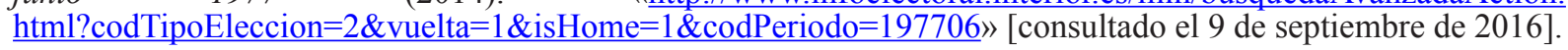


ellos el Movimiento de Alcaldes ${ }^{22}$ y el $\mathrm{PNV}^{23}$, e incluso el gobierno vasco en el exilio ${ }^{24}$. En esa provincia, tras constatar la imposibilidad de completar una lista electoral, la UCD apoyó la candidatura de Demócratas Independientes Vascos (DIV) ${ }^{25}$, encabezada por Escudero, que se presentó bajo el lema Una unión foral para la autonomía ${ }^{26}$ y logró 15.505 votos, lo que representaba el 3,54\% de los habitantes de esa provincia con derecho a voto y el 4,62\% de los que votaron ${ }^{27}$, claramente insuficiente para obtener representación parlamentaria.

La UCD logró en las elecciones de 1977 siete escaños en el Congreso y cinco en el Senado, entre ellos Fernández Palacios y Jaime Ignacio del Burgo. Mientras, los dos partidos mayoritarios tras las elecciones, PSE-PSOE y PNV, se aprestaron a implementar el compromiso autonómico suscrito y crear en consecuencia la Asamblea de Parlamentarios Vascos (APV), como un sujeto político pleno en representación del pueblo $\mathrm{vasco}^{28}$, en aras de la aspiración unitaria regional. De tal manera, la APV quedó constituida a los cuatro días de los comicios en la que había sido la sede tradicional de las entonces inexistentes juntas generales vizcaínas, el organismo foral de solo una de las cuatro provincias. Al acto en la Casa de Juntas de Guernica se sumó la UCD de Vizcaya ${ }^{29}$, pero no la de Álava y de Navarra.

Un día antes, los parlamentarios de la UCD navarra expresaron en declaraciones a la prensa el planteamiento de su formación a favor de la vía foral, entendida en su propia dimensión provincial. Del Burgo señaló: "Queremos sobre todo seguir siendo navarros, sin entrar en Euskadi". "Reclamamos solemnemente el derecho de Navarra a decidir su destino. Es el pueblo navarro el único que puede hacerlo", añadió. Del Burgo dejó claro en aquella comparecencia ante los medios de comunicación, acompañado del resto de parlamentarios navarros de la UCD, que no acudirían al día siguiente al acto de constitución de la APV. El senador explicitaba la estrategia que seguirían:

\begin{abstract}
Nuestra postura en las Cortes ha de ser de apoyo total y sin reservas de autonomía de las provincias hermanas. Si Navarra ha de recuperar su propia autonomía foral, no menos han de conseguirlo Vizcaya, Guipúzcoa y Álava. Pero Navarra debe ser una comunidad regional unitaria.
\end{abstract}

Unas declaraciones en las que sus protagonistas tampoco ocultaron la filiación tradicionalista de tal foralismo. Así, el senador José Gabriel Sarasa Miquélez sentenció: “En

\footnotetext{
22 "Recepción en La Cumbre", en El Diario Vasco, 29 de agosto de 1976, p. 24.

${ }^{23}$ Mallo, Albino, "Tengo amigos del PNV", en Unidad, 4 de septiembre de 1976, pp. 1 у 3.

24 "El Gobierno propone una reunión con Leizaola", en El Diario Vasco, 23 de agosto de 1977, pp. 1 y 8.

${ }^{25}$ Oreja Aguirre, Marcelino, Memoria y esperanza. Relatos de una vida, Madrid, La esfera de los libros, 2011, p. 205.

26 “Los candidatos exponen los programas", en El Diario Vasco, 31 de mayo de 1977, p. 24.

27 Gobierno de España, Ministerio del Interior, Consulta de resultados electorales, Congreso junio 1977 (2014). .http://www.infoelectoral.interior.es/min/busquedaAvanzadaAction. html? codTipoEleccion=2\&vuelta=1\&isHome=1\&codPeriodo=197706» [consultado el 9 de septiembre de 2016]. ${ }^{28}$ Tamayo Salaberría, Virginia, La autonomía vasca contemporánea. Foralidad y estatutismo (1975-1979), Oñati (Guipúzcoa), Instituto Vasco de Administración Pública, 1994, p. 244.

${ }^{29}$ Portell, José María, "Constituida la Asamblea de Parlamentarios Vascos", en La Gaceta del Norte, 21 de junio de 1977 , pp. 1 y 8.
} 
el Centro Democrático de Navarra hoy (...) se siente el carlismo navarro, un carlismo de raíz popular". "En mi interior sigo siendo carlista", añadió30, quien había sido concejal por representación familiar en el consistorio franquista del Ayuntamiento de Pamplona de la década de los sesenta.

En cuanto a la ausencia de los parlamentarios centristas alaveses en la Casa de Juntas de Guernica, los diputados Pedro Morales Moya y Jesús María Viana Santa Cruz, y el senador Alfredo Marco Tabar, adujeron una semana más tarde en declaraciones a la prensa que no habían formado parte de la APV "por entender que la autonomía foral es el punto límite a que su provincia aspira". Es decir, aseguraban que su pretensión en materia descentralizadora era provincial, mediante la restauración foral, aunque expresaban su respeto a los planteamientos regionales de la UCD vizcaína y se comprometían a formar un grupo de trabajo para unificar posturas $^{31}$. Todo ello en el día en que se reunieron en Madrid todos los parlamentarios de la coalición elegidos en los recientes comicios para formar un grupo parlamentario y en el que se planteó la constitución de UCD como partido político ${ }^{32}$.

\section{Planteamientos dispares}

Ante tal endurecimiento del planteamiento provincialista, Suárez convocó a una reunión el 28 de junio a los doce diputados y senadores vasco-navarros de su coalición electoral. De ellos, tan solo los tres vizcaínos estaban de acuerdo con lo planteado por la APV de pretender una autonomía regional vasco-navarra, mientras que los seis navarros la rechazaban y pretendían formar un grupo propio regional navarro. La reunión duró dos horas y en el curso de la misma, el presidente del gobierno logró al menos que los parlamentarios alaveses suavizasen su postura provincialista $^{33}$. Estratégicamente, Suárez no podía permitir que se diluyera el peso obtenido en las elecciones por la UCD, mediante la renuncia de plano de Álava a integrarse en una futura entidad, aunque fuera ya solo vascongada, en la medida en que la posibilidad de que fuera vasconavarra había quedado abortada no solo por los parlamentarios centristas navarros, sino sobre todo por la taxativa negativa a integrarse en Euskadi de la carlo-franquista Diputación Foral de

\footnotetext{
${ }^{30}$ Arbizu. M.A., "Declaraciones de los diputados del Centro Democrático por Navarra", en La Gaceta del Norte, 19 de junio de 1977, p. 7.

31 "Suárez con parlamentarios vascos de UCD", en La Voz de España, 29 de junio de 1977, p. 3.

32 "La UCD: Partido político y unión parlamentaria", en $A B C, 29$ de junio de 1977, p. 1.

33 "Los doce parlamentarios vascos de UCD se entrevistaron con el presidente Suárez", en La Gaceta del Norte, 29 de junio de 1977, p. 6.
} 
Navarra que, según la vigente ley de $1841^{34}$, era el único interlocutor del gobierno, amagando incluso con desarrollar una interpretación soberanista de la foralidad del viejo reino ${ }^{35}$.

A los dos días de la reunión con los parlamentarios vasco-navarros, celebrada en el palacio de la Moncloa ${ }^{36}$, los dos diputados y el senador alaveses emitieron un comunicado en el que aceptaban participar en la autonomía regional vascongada, poniendo como límite expreso que "no se comprometiera la unidad de España". "Por constituir Álava parte integrante del País Vasco, estamos interesados en defender la autonomía regional de la misma", señalaban ahora los parlamentarios alaveses de la UCD, que mostraban además su intención de participar en la APV a partir de ese momento ${ }^{37}$.

Morales, Viana y Marco Tabar publicaron el 30 de junio otro comunicado en Norte Exprés, el único periódico alavés, en el que hacían a sus lectores provinciales una justificación retrospectiva de su actuación, asegurando que "a lo largo de la campaña electoral, verbalmente y por escrito, se proclamaron a favor de la autonomía del País Vasco con la única limitación expresa de que no se comprometiera la unidad de España”. Y admitían que la UCD a nivel nacional era regionalista, ya que "tiene adquirido el compromiso de recoger en la nueva Constitución que se redacte el tema de las autonomías regionales". Pero, insistían, como "Álava tiene ya reconocido un cierto grado de autonomía" gracias al disfrute del neoforal Concierto Económico, deben ser las juntas generales las que desempeñen el "protagonismo regional”. Las juntas “deben ser (...) la institución que dirija y encauce el entendimiento con las provincias hermanas". Entendían que tal gradualismo regional era "compatible con el respeto de las peculiaridades forales de Álava" ${ }^{38}$. El protagonismo otorgado a las provincias en la futura construcción regional había sido diseñado por el gobierno Suárez sobre los trabajos de la comisión descentralizadora para Guipúzcoa y Vizcaya ${ }^{39}$, creada en los últimos días de vida del dictador ${ }^{40}$ y cuyas conclusiones no democráticas ${ }^{41}$ fueron matizadas por el gabinete reformista en el decreto-ley de 4 de marzo de restauración de los organismos forales provinciales, cuya implementación quedaba pospuesta a la existencia de comicios municipales democráticos ${ }^{42}$.

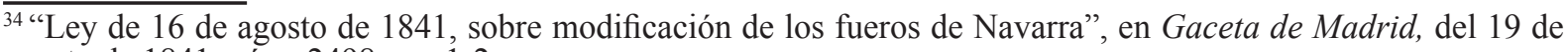
agosto de 1841, núm. 2498, pp. 1-2.

${ }^{35}$ Baraibar Etxeberria, Álvaro y Juan María Sánchez-Prieto, “Las ideas fuerza de la Transición. II La controversia Navarra-Euskadi”, en Ramírez Sádaba, José Luis (dir.), Democratización y amejoramiento foral. Una historia de la Transición en Navarra (1975-1983), Pamplona, Gobierno de Navarra: Departamento de Presidencia e Interior, 1999, pp. 168-177.

36 "La defensa de la autonomía del País Vasco es compatible con el respaldo de las peculiaridades forales de Álava", en Norte Exprés, 30 de junio de 1977, p. 28.

37 “Se manifiestan por la autonomía siempre que no se comprometa la unidad de España", en La Gaceta del Norte, 1 de julio de 1977 , p. 6.

38 "La defensa de la... op. cit., p. 28.

${ }^{39}$ ACP, FSGT, Caja 2274, p. 367, “Acta de la sesión plenaria celebrada por la Comisión para estudio de la implantación de un régimen administrativo especial para las provincias de Vizcaya y Guipúzcoa, el día trece de octubre de mil novecientos setenta y seis".

${ }^{40}$ Decreto 3142/1975, de 7 de noviembre, por el que se crea una Comisión para el estudio de la implantación de un régimen administrativo especial para las provincias de Vizcaya y Guipúzcoa, en Boletín Oficial del Estado, del 3 de diciembre de 1975, núm. 290, p. 25176.

${ }^{41}$ Echevarría Pérez-Agua, Juan José, La constitucionalización de la ... op. cit., p. 400.

${ }^{42}$ Real Decreto-Ley 18/1977, de 4 de marzo, para la restauración de las Juntas Generales de Guipúzcoa y Vizcaya, en Boletín Oficial del Estado, del 17 de marzo de 1977, núm. 65, pp. 6200-6201.
} 
La intervención de Suárez fue clave para que los parlamentarios de la UCD alavesa aceptasen formar parte de la APV y contribuyeran a incluir a su provincia en la futura región vasca. Aún así, las reticencias se mantendrán. En ello influyó que la UCD no era aún un partido político y que la coalición fue montada desde el gobierno, como una mera plataforma para Suárez ${ }^{43}$, agrupando en muchas provincias a dirigentes locales, que en muchos casos carecían de planteamientos generales consensuados, prevaleciendo los propios. De hecho, la UCD nació de la fusión de propuestas diferentes: aquellas dimanadas de cada una de las provincias y las que lideraban los dirigentes nacionales, con Suárez a la cabeza ${ }^{44}$. Tal extremo se unía al hecho de que la UCD "carecía de una opción firme en materia autonómica" 45 , como señaló posteriormente Miguel Herrero Rodríguez de Miñón, entonces secretario general del ministerio de Justicia y futuro padre de la Constitución de 1978.

El 20 de julio la APV celebró su segunda reunión de trabajo, esta vez en la Diputación Provincial de Vizcaya, y a ella acudieron ya los parlamentarios de la UCD de Álava, siendo designado Viana como uno de los cuatro secretarios del organismo ${ }^{46}$. A diferencia de la de navarra, la Diputación Foral de Álava apoyaba la participación de los parlamentarios de la provincia en la APV. De hecho, días antes, había ofrecido a la asamblea un local, funcionarios y un letrado para que la Secretaría Técnica de la APV se ubicara en Vitoria, lo que fue aprobado en la reunión ${ }^{47}$. La predisposición alavesa ofreció aquel mismo día otra muestra: el Ayuntamiento de Vitoria acordó en días solemnes izar la ikurriña ${ }^{48}$. Veinte días antes, el exprocurador Marco Tabar, hasta entonces teniente de alcalde, se había convertido en el nuevo alcalde ${ }^{49}$. Diputación Foral, Ayuntamiento de Vitoria y los parlamentarios de la UCD alaveses actuaban todos al unísono, distanciándose de la situación en Navarra.

Tres días después de la segunda reunión de trabajo de la APV, Del Burgo acudió a Madrid, manteniendo diversas reuniones en el seno de la UCD y publicitando un documento, firmado por los seis parlamentarios ${ }^{50}$, en el que mostraban su disconformidad con las intenciones de la asamblea de parlamentarios de incluir a Navarra en un marco unitario vasco, al considerar que tal pretensión resultaba "un flagrante contrafuero por vulnerar abiertamente el régimen paccionado entre Navarra y el Estado fijado por la Ley de 1841" "51, la norma por la que el viejo reino se había convertido en una provincia española, pero con una autonomía desconocida hasta entonces $^{52}$.

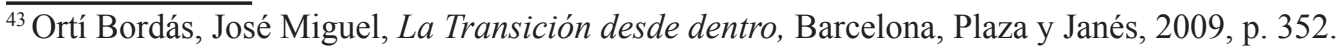

${ }^{44}$ Gascó Escudero, Patricia, "Las estructuras orgánicas de UCD en los ámbitos nacional y provincial (1977-1982)", en Historia del Presente 30, 2 (2017), p. 93.

${ }^{45}$ Herrero Rodríguez de Miñón, Miguel, Derechos Históricos y Constitución, Madrid, Taurus, 1998, p. 68.

${ }^{46}$ Tamayo Salaberría, Virginia, La autonomía vasca contemporánea ... op. cit., p. 246.

${ }^{47}$ Letamendía, Francisco, Historia del nacionalismo vasco y de ETA. ETA en la transición (1976-1982), volumen II, San Sebastián, R\&B, 1994, p. 60.

48 "La ikurriña en el Ayuntamiento de Vitoria", en El Diario Vasco, 21 de julio de 1977, p. 4.

49 "D. José Casanova cesó en el cargo y el Sr. Marco Tabar es el nuevo alcalde", en Norte Exprés, 1 de julio de 1977 , p. 14.

50 "Nuevo ataque de los parlamentarios navarros de UCD", en La Gaceta del Norte, 29 de julio de 1977, p. 7.

${ }^{51}$ Tamayo Salaberría, Virginia, La autonomía vasca contemporánea ... op. cit., p. 247.

${ }^{52}$ Burgo, Jaime Ignacio del, El Pacto Foral... op. cit., p. 34.
} 
La UCD de Navarra también polemizó con el PSE-PSOE. Fue a raíz del proyecto de preautonomía regional presentado por los socialistas en la APV, que proponía la creación de una Diputación General Provisional del País Vasco con competencias sobre las cuatro provincias y cuyas decisiones debían ser refrendadas por el gobierno vasco en el exilio ${ }^{53}$, un ejecutivo que nunca había tenido ascendente alguno sobre Navarra. Tales pretensiones ocasionaron la crítica de la UCD del viejo reino. El senador Pegenaute sentenció que la diputación general prevista en el proyecto socialista no respetaba "la peculiaridad foral de Navarra" ${ }^{2}$. Pero también de la UCD de Álava, el otro territorio que había conservado su foralidad, que criticó que en la diputación general unitaria no estuvieran representadas en igual número las cuatro provincias A la par, la Diputación Foral de Álava explicitó su rechazo por no reconocer el proyecto socialista el Concierto Económico, la singularidad foral del territorio menos poblado ${ }^{55}$.

En cambio, el proyecto presentado días después por el PNV se amparaba en los derechos históricos de cada uno de los territorios y hablaba de un "proyecto de autonomía para Álava, Guipúzcoa, Navarra y Vizcaya", sin mencionar a Euskadi. El órgano unitario no solo era confederal, como el socialista, sino igualitario en su composición. Otorgaba además a cada territorio la posibilidad de veto de las decisiones de la Asamblea Confederal del País Vasco, y reconocía explícitamente las singularidades forales navarras y alavesas ${ }^{56}$. Todo ello evitó que la UCD de Álava saliera en tromba contra el borrador del partido jeltzale $e^{57}$, llegando a afirmar el diputado Morales que el borrador "del PNV tiene muchas cosas de acuerdo con nuestras ideas". En toda la consideración de los centristas alaveses subyacía el respeto a las provincias, algo que consideraban "la base y el fundamento de todo" 58 . Menor meditación provincial tuvo la UCD de Vizcaya, quien también alabó el proyecto jeltzale. Así, lo hizo su cabeza de lista en los comicios de junio, Juan Echevarría Gangoiti, miembro de la RSBAP y ex rector de la Universidad Autónoma de Bilbao,quien dijo a la prensa que la UCD vizcaína estaba más próxima al proyecto del PNV que al del PSOE: "Nosotros nos encontramos más cerca del nacionalismo vasco", llegó a decir, tras confirmar que la UCD no elaboraría su propio borrador preautonómico $^{59}$. Quedaba así configurada en el ámbito vascongado una UCD vizcaína más regionalista y una UCD alavesa más provincialista.

La cuestión igualitaria del número de representantes provinciales en el futuro órgano unitario vasco no era baladí, ya que afectaba a la consideración de democrático del mismo, en

\footnotetext{
53 "El Gobierno vasco en el exilio, invitado a regresar", en El Diario Vasco, 11 de agosto de 1977, pp. 1 y 8.

54 "Dirigentes del (sic) UCD y PNV se reunieron para tratar sobre la autonomía del País Vasco y Navarra", en $E l$ Correo Español-El Pueblo Vasco, 31 de agosto de 1977, p. 8.

55 "La Diputación Foral de Álava y los parlamentarios de UCD salen al paso del proyecto de autonomía del PSOE", en La Gaceta del Norte, 14 de agosto de 1977, p. 7.

56 "Proyecto de decreto-ley de un régimen provisional preautonómico para Navarra, Álava, Guipúzcoa y Vizcaya", en El Correo Español-El Pueblo Vasco, 31 de agosto de 1977, p. 1.

57 "Dirigentes del (sic) UCD y... op. cit., p. 8.

58 "Rueda de prensa con los parlamentarios alaveses de UCD", en El Correo Español-El Pueblo Vasco, 17 de septiembre de 1977, p. 9.

59 “Autonomía: la postura de UCD cercana a la del PNV", en El Correo Español-El Pueblo Vasco, 6 de septiembre de 1977 , p. 9.
} 
la medida en que existía una diferencia poblacional evidente: los vizcaínos duplicaban a los navarros (1.043.310 frente a 464.867) y casi a los guipuzcoanos (631.004), cuadruplicando a los alaveses $(204.323)^{60}$.

\section{Aceptación de la vía foral y uniprovincial navarra}

El 6 de septiembre, la UCD, cuando llevaba solo un mes constituida como partido político, celebró una reunión de parlamentarios y dirigentes vasco-navarros en Vitoria con el objetivo de cohesionar la formación, aclarando las diferentes posiciones mantenidas por cada provincia respecto a la región vasco-navarra y a su concreción preautonómica. Estuvieron presentes en aquel cónclave los parlamentarios vizcaínos Fernández Palacios y Ricardo Echanove Tuero, los alaveses Viana, Morales y Tabar, y los navarros Jesús Ignacio Astráin Lasa, Jesús Aizpún Tuero, Del Burgo y Sarasa. Incluso asistió a la reunión una delegación del partido en Guipúzcoa ${ }^{61}$, laúnica provincia donde UCD no había presentado candidatura en las elecciones; estuvo encabezada por Jaime Mayor Oreja ${ }^{62}$, quien impulso su creación tras el fracaso electoral de DIV ${ }^{63}$, formación en la que había compartido lista con Escudero ${ }^{64}$. En aquella reunión, los parlamentarios más partidarios de la regionalización, los vizcaínos, asumieron "el total respeto y apoyo de las provincias vascongadas a los parlamentarios de la UCD de Navarra” y, recíprocamente, la UCD navarra respaldaba el planteamiento de "autonomía foral de Álava, Guipúzcoa y Vizcaya", prevaleciendo por tanto el provincialismo sobre el regionalismo en aquella primera reunión de los centristas vasco-navarros. La foralidad era, pues, el único elemento compartido por todas y cada una de las distintas delegaciones del partido en cada provincia. De hecho, todos los reunidos acordaron apoyar "el restablecimiento de las autonomías de acuerdo con los derechos históricos de cada provincia" 65 .

Tal aceptación, permitió a la UCD vascongada reorganizarse, consciente de que los buenos resultados del 15 de junio no se correspondían con el bajo nivel de militancia en los dos territorios donde se había podido presentar. Respecto al tercero, Guipúzcoa, el objetivo del partido centrista pasaba por asentarse también allí. El 15 de octubre, la UCD guipuzcoana

\footnotetext{
${ }^{60}$ Instituto Nacional de Estadística, Población de hecho desde 1900. Nacional, Comunidades Autónomas y Provincias (2016). «http://www.ine.es/jaxiT3/Datos.htm?t=3035» [consultado el 9 de septiembre de 2016].

61 "UCD: la autonomía, basada en los derechos históricos de cada provincia", en El Correo Español-El Pueblo Vasco, 7 de septiembre de 1977, p. 10.

${ }^{62}$ Sobrino de Marcelino Oreja Aguirre y futuro ministro del Interior en el gobierno de José María Aznar.

${ }^{63}$ Landaberea, Eider, "España, lo único importante: El centro y la derecha española en el País Vasco durante la Transición (1975-1980)", en Historia del Presente 19, 1 (2012), pp. 53-98, p. 56.

64 "Los candidatos exponen... op. cit., p. 24.

65 “Restablecimiento de las autonomías según los derechos históricos de cada provincia”, en La Gaceta del Norte,

7 de septiembre de 1977, pp. 1 y 7.
} 
se presentó en el hotel María Cristina de San Sebastián. Su primer secretario general, Mayor Oreja, abogó por constituir con el partido en Álava y Vizcaya una UCD del País Vasco, sin mencionar en ningún momento la organización del partido en Navarra ${ }^{66}$. En el ideario de la UCD guipuzcoana se abogaba por la recuperación del régimen foral para la provincia, en el marco autonómico del País Vasco ${ }^{67}$. Uno de sus afiliados más insignes fue el ministro Marcelino Oreja $^{68}$, quien asistió a la presentación pública del partido el 13 de noviembre en el teatro Astoria de la capital donostiarra ${ }^{69}$, y quien también estuvo presente en la reunión de dirigentes vasco-navarros de Vitoria ${ }^{70}$.

También Suárez colaboró en la labor de realzar a la UCD guipuzcoana, recibiendo días antes en el palacio de la Moncloa a una delegación de quince miembros, encabezados por Mayor Oreja $^{71}$. La estrategia de la UCD en aquel territorio pasaba por abundar en el mensaje foralista provincial, lo que estratégicamente era un acierto en una provincia donde había un considerable voto por esa opción, huérfano tras la debacle de Guipúzcoa Unida (GU), la candidatura electoral en la órbita de Alianza Popular, donde se había agrupado el carlofranquista equipo directivo de la diputación guipuzcoana, que había logrado 27.048 sufragios al Congreso el 15 de junio, el $8,06 \%$ de los votos emitidos en la provincia y el 6,18 \% del censo. Pero tal estrategia chocaba también con la de la UCD vizcaína que pretendía hacerse con el voto de la unitaria Democracia Cristiana Vasca, otra formación en descomposición, debido igualmente a sus malos resultados electorales (un magro 2,52\% y 1,94\% ${ }^{72}$ ), atrayendo a sus exdirigentes como Julen Guimón Ugartechea $^{73}$.

Pero, para Suárez, la atención había que centrarla en la UCD de Álava y en su encaje en la del País Vasco. El 25 de noviembre, en Durango, se reunieron representantes centristas de las provincias vascongadas con "el objeto de unificar criterios para una próxima constitución de la UCD vasca", según rezó el comunicado oficial de aquella reunión, que creó una comisión ejecutiva del partido para las tres provincias ${ }^{74}$. La UCD del País Vasco, sin Navarra, echaba a andar, bajo la presidencia del dirigente alavés Viana ${ }^{75}$, lo que evidenciaba un peso desmesurado de la provincia meridional como contrapartida a la participación de esta en la UCD vascongada. El 2 de diciembre celebró en Vitoria su primer encuentro, abogando por "actuar combinadamente

\footnotetext{
${ }^{66}$ Echeverri, Carlos, "La UCD quiere ser la tercera gran fuerza de Euskadi”, en La Voz de España, 16 de octubre de 1977, p. 4.

67 "Motivos por los que se ha creado UCD de Guipúzcoa", en La Voz de España, 16 de octubre de 1977, p. 4.

68 "Marcelino Oreja, afiliado de UCD de Guipúzcoa", en El Diario Vasco (San Sebastián), 12 de noviembre de 1977, p. 3.

${ }^{69}$ Echeverri, Carlos, “Ayer se presentó UCD de Guipúzcoa”, en Unidad, 14 de noviembre de 1977, p. 5.

70 "UCD: la autonomía, basada... op. cit., p. 10.

71 "Suárez recibió a UCD de Guipúzcoa", en La Voz de España, 27 de octubre de 1977, p. 32.

72 Gobierno de España, Ministerio del Interior, Consulta de resultados electorales, Congreso junio 1977 (2014). «http://www.infoelectoral.interior.es/min/busquedaAvanzadaAction. html? codTipoEleccion=2\&vuelta=1\&isHome=1\&codPeriodo=197706» [consultado el 9 de septiembre de 2016]. 73 “Julen Guimón decide ingresar en UCD”, en El Diario Vasco (San Sebastián), 12 de noviembre de 1977, p. 3.

74 "Hacia una UCD vasca", en El Diario Vasco, 26 de noviembre de 1977, p. 5.

${ }^{75}$ Oreja Aguirre, Marcelino, Memoria y esperanza. Relatos... op. cit., p. 205.
} 
en el ámbito regional sin que ello sea obstáculo a la actuación de cada provincia y el respeto de sus peculiaridades" ${ }^{\prime 76}$.

La potenciación de la UCD de Álava tenía para Suárez otra virtualidad, aquella derivada de su capacidad de influir en el seno de la APV. Ya el 19 de septiembre, los parlamentarios aprobaron el proyecto preautonómico consensuado por el PSE y PNV, que creaba un órgano unitario confederal, pero no del todo igualitario ${ }^{77}$. Una de las dos únicas enmiendas admitidas por los partidos mayoritarios fue aquella presentada por la UCD de Álava, que otorgaba el derecho de veto a cada una de las provincias constituyentes de la futura entidad regional ${ }^{78}$.

El proyecto aprobado fue negociado con el gobierno por tres parlamentarios: José María Benegas, Juan de Ajuriaguerra y Juan Echevarría, uno por cada uno de los tres partidos más votados en los comicios del 15 de junio. Pero, Viana, de la UCD alavesa, logró sustituir al dirigente de su partido en Vizcaya en dos de las seis reuniones ${ }^{79}$ que mantuvo el ministro adjunto para Relaciones con las Regiones, Manuel Clavero Arévalo, con los parlamentarios y en las que finalmente se acordó que el órgano unitario, el Consejo General del País Vasco (CGPV), no solo sería confederal, sino plenamente igualitario ${ }^{80}$, con lo que los centristas de la provincia meridional alcanzaban su reivindicación prioritaria para aceptar su integración en el País Vasco.

Resuelta esta crucial cuestión, el gobierno Suárez se centró en la negativa de la UCD navarra a aceptar lo acordado por Clavero con la APV. Ya el 25 de octubre, los centristas navarros presentaron a la prensa un documento elaborado por Del Burgo y aprobado por el comité regional del partido en el viejo reino, en el que detallaba su programa foral, tal como era intitulado el mismo, en el que se proclamaba: "En la actual etapa constituyente, la UCD de Navarra entiende, que a diferencia de otras regiones españolas, Navarra no precisa de ningún régimen preautonómico, puesto que su régimen foral garantiza a la región un marco de autonomía". Tal hecho, añadía, "no excluye el derecho de la región a perfeccionar su autonomía foral a partir de su propio sistema de actualización, que no es otro que el del pacto entre el Estado y el poder foral". Dicha actualización, en un marco provincial, no regional, debía hacerse "mediante instituciones representativas y democráticas" ${ }^{81}$, cuestión relevante en la que difería con lo pretendido por la Diputación Foral de Navarra, lo que posibilitaría en una fase posterior prescindir del equipo dirigente de la corporación y asumir los parlamentarios navarros la dirección de los órganos provinciales autonómicos. La mayoría carlo-franquista de la diputación, encabezada por el excapitán de Requetés Amadeo Marco Ilincheta, se había opuesto a los intentos de la minoría de la corporación favorable a la democratización de las instituciones

\footnotetext{
76 "Se constituye UCD Vasca", en El Diario Vasco, 3 de diciembre de 1977, p. 5.

77 "Los parlamentarios vascos aprobaron el proyecto preautonómico", en El Diario Vasco, 20 de septiembre de 1977 , p. 7.

${ }^{78}$ Viloria, Juan Carlos, "La asamblea de parlamentarios vascos aprobó el proyecto autonómico transitorio para el País Vasco", en El Correo Español-El Pueblo Vasco, 20 de septiembre de 1977, pp. 1 y 9.

${ }^{79}$ Echevarría Pérez-Agua, Juan José, La constitucionalización de la ... op . cit., pp. 525-537.

80 "Este es el Decreto-Ley", en El Diario Vasco, 26 de noviembre de 1977, p. 3.

${ }^{81}$ Gortari Unanua, Joaquín, La transición política en Navarra, 1976-1978, volumen II, Pamplona, Departamento de Presidencia, 1995, p. 123.
} 
forales en una fecha tan temprana como el 21 de julio de $1976^{82}$, después de que los tres diputados forales partidarios de ella lo publicitaran a través de la prensa ya en febrero anterior ${ }^{83}$. A partir de ahí, la posición de los cuatro diputados forales de la mayoría de la corporación consistió en ignorar a los parlamentarios elegidos el 15 de junio de 1977 al considerar a la diputación como el único interlocutor con el gobierno sobre el futuro de Navarra ${ }^{84}$, basándose en la ley de 1841. Para ello, la mayoría de la diputación ideó una estrategia de restauración foral que pretendía recuperar para la provincia todas las competencias que en algún momento el antiguo reino había disfrutado, incluido el pase foral (derecho de sobrecarta en el antiguo régimen foral navarro), en una interpretación soberanista, basada precisamente en la mencionada norma ${ }^{85}$, considerada como paccionada por la interpretación tradicionalista de la foralidad, argumentándola en la vinculación eqüae principal de Navarra con la corona de Castilla ${ }^{86}$.

Mientras tanto, la UCD navarra logró un triunfo al aceptar el PSE-PSOE una de sus demandas más significativas, que ya habían expuesto en su programa foral del 25 de octubre: la creación del Consejo de Parlamentarios de Navarra. Desde la aparición de la APV, los centristas navarros pretendieron contrarrestar esa institución mediante la constitución de una asamblea de parlamentarios navarros. La UCD pretendió que así se denominase, pero fue condición para que los socialistas navarros aceptasen integrarse y arrastrasen a ello a Manuel de Irujo, el único parlamentario logrado por el nacionalismo vasco en Navarra, que se adoptara la designación de CPN, que no era una contraposición en términos formales a la APV. Se constituyó el 25 de noviembre en la sede de la diputación, en el palacio de Navarra ${ }^{87}$. En la nota oficial que hizo pública el nuevo organismo, quedaba explicitado que la participación en él no presuponía renuncia de las formaciones a otros objetivos, como era la integración de Navarra en Euskadi, lo que posibilitó que el PSE y el PNV se sumaran. Así, se señalaba: “El Consejo es una institución de diálogo y encuentro de los parlamentarios navarros, sin que su constitución prejuzgue la renuncia a los postulados defendidos por los partidos políticos representados en el mismo"88. De hecho, un día después, la APV se reunió, la cuarta vez que lo hacía, reafirmándose en sus posiciones y decidiendo mandar a Suárez y a Clavero sendos telegramas, instándoles a implementar lo acordado, es decir, que dejaran abierta la puerta para la incorporación de Navarra al CGPV ${ }^{89}$. Por lo tanto, pese a los avances logrados por la UCD navarra, las espadas seguían en alto.

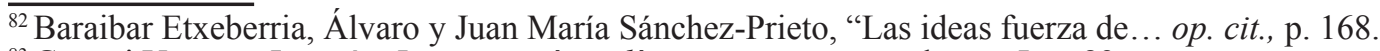

${ }^{83}$ Gortari Unanua, Joaquín, La transición politica en ... op. cit., volumen I, p. 82.

${ }^{84}$ Gortari Unanua, Joaquín, La transición política en ... op. cit., volumen II, p. 131.

${ }^{85}$ Baraibar Etxeberria, Álvaro y Juan María Sánchez-Prieto, "Las ideas fuerza de... op. cit., pp. 173-176.

${ }^{86}$ Baraibar Etxeberria, Álvaro, Extraño federalismo. La vía navarra a la democracia, 1973-1982, Madrid, Centro de Estudios Políticos y Constitucionales, 2004, p. 357.

${ }^{87}$ Ibidem, p. 147.

${ }^{88}$ Gortari Unanua, Joaquín, La transición política en ... op. cit., volumen I, p. 199.

89 "La Asamblea de Parlamentarios ratifica el texto del proyecto preautonómico", en La Voz de España, 27 de noviembre de 1977, pp. 1 y 3.
} 
El impasse duró poco más de dos semanas. El 14 de diciembre, Suárez recibió a una delegación de la UCD del País Vasco, transmitiendo que el gobierno buscaba una vía de consenso entre la APV y el CPN ${ }^{90}$. De hecho, los triunfos de la UCD navarra y la postura soberanista de la Diputación Foral de Navarra habían obligado al gabinete a paralizar lo acordado por Clavero con la APV, hasta el punto que fue toda una descalificación para el ministro para las Regiones, concretada en el Consejo de Ministros del 17 de diciembre, que impelió a este a lograr "el consenso de los representantes parlamentarios de los distintos partidos políticos de las provincias afectadas"91; es decir, también de los centristas navarros.

La reacción de la APV fue presionar al gobierno, exigiéndole respetar lo acordado, medida que no contó con el apoyo de la UCD alavesa, pero sí de la vizcaína, en dos reuniones previas mantenidas el 15 y 16 de diciembre, en las que los partidos parlamentarios buscaron el apoyo de los extraparlamentarios ${ }^{92}$. Un día después se reunió formalmente la APV, la quinta vez que lo hacía, evidenciándose las diferencias en el seno de la UCD. Por un lado, la vizcaína, que no renunciaba a dejar abierta la integración de Navarra en el País Vasco, tal como había recogido el proyecto de la APV, y por otro, la UCD alavesa que respaldaba a la navarra en su vía foral provincial. De hecho, el consenso había sido la tónica de aquella reunión de la APV, hasta que llegaron los centristas alaveses Viana y Morales, que impugnaron todo lo acordado. El primero adujo que lo pretendido por la APV no era respetuoso con las "democráticas opiniones de los parlamentarios navarros" de su partido, abogando por "llegar a un consenso" con ellos como única manera de resolver el contencioso ${ }^{93}$. Las palabras del diputado centrista llevaron la tensión a la asamblea. Viana insistió en que era necesario y con carácter previo llegar a un acuerdo con la UCD de Navarra, tras lo que quiso dejar claro que no hablaba en representación de los centristas del viejo reino, aunque había tenido conversaciones con ellos antes de acudir a la reunión de la APV. PSOE y PNV replicaron a Viana, pero también la UCD de Vizcaya. Juan Echevarría pidió un nuevo receso, que aprovechó para hablar con Viana y Morales ${ }^{94}$.

Tras quince minutos de conversaciones ${ }^{95}$, los parlamentarios alaveses aceptaron suavizar su postura, dejando su oposición en una abstención y ratificando su apoyo, tal como habían hecho en la cuarta reunión plenaria, al proyecto de decreto-ley negociado con el gobierno, aunque insistían en que era primordial llegar a un consenso previo con la UCD navarra. De esa manera, el partido de Suárez en Álava acabó con el frente unido de los parlamentarios vascos respecto a la cuestión navarra.

\footnotetext{
90 "Suárez busca una vía de consenso", en El Diario Vasco, 15 de diciembre de 1977, p. 5.

91 "Preautonomía vasca [:] seguir negociando", en El Diario Vasco, 17 de diciembre de 1977, p. 1.

92 "Hoy, la Asamblea de Parlamentarios estudiará medidas de presión", en La Voz de España, 17 de diciembre de 1977, p. 3.

93 “La Asamblea de Parlamentarios no cede ni un ápice”, en El Diario Vasco, 18 de diciembre de 1977, pp. 1 y 36.

94 "Los parlamentarios vascos, unidos", en La Voz de España, 18 de diciembre de 1977, p. 4.

95 "La Asamblea de Parlamentarios...", en El Diario Vasco..., 18 de diciembre de 1977, pp. 1 y 36.
} 
Tras cuatro horas y media de reunión ${ }^{96}$, quedó aprobado, con la abstención de los parlamentarios de la UCD alavesa: "Mantener inalterable y en sus términos el texto que negociado con el Gobierno, fue aprobado y suscrito unánimemente en la reunión anterior de la asamblea" "97. Reconocía así la APV la fragilidad de la unión de los parlamentarios vascos, evidenciada en la última reunión; vulnerabilidad mostrada en la nota que hicieron pública Viana y Morales:

Los parlamentarios de UCD de Álava (...) quieren dejar constancia de su abstención con respecto al comunicado de hoy, en razón a que sopesados los inconvenientes y ventajas del mismo, entienden que es primordial aunar por vía de consenso la conformidad de los parlamentarios navarros que han expuesto sus razones democráticas en defensa de sus tesis y ello por el bien general del país. ${ }^{98}$

El 20 de diciembre, el vicepresidente Fernando Abril Martorell se reunió con los dirigentes de la UCD de las tres provincias vascongadas, entre ellos Echevarría y Viana. Ese mismo día, el partido centrista había clarificado su posición sobre la descentralización en una junta de su Comité Ejecutivo con los secretarios provinciales y regionales. En aquel cónclave nacional, la UCD acordó respetar en los regímenes preautonómicos "el derecho de cada territorio a expresar libre y democráticamente por los procedimientos que establezca la Constitución, su voluntad de incorporarse a una región determinada" $"$. La intervención en el asunto vasco-navarro de Abril Martorell, con mayor peso político que Clavero en el seno del gabinete, se mostró decisiva, consiguiendo que Suárez aceptase que Navarra pudiese celebrar un referéndum para decidir su inclusión en el País Vasco en período preconstitucional ${ }^{100}$, lo que de haberse concretado hubiera supuesto una notable excepción en el proceso descentralizador de la transición democrática.

El 28 de diciembre, la APV celebró su sexta reunión, aceptando los parlamentarios la negociación de los diputados y senadores navarros sobre el futuro del viejo reino ${ }^{101}$. Esta se concretó en dos sesiones en el Congreso de los Diputados, celebradas el $29^{102}$ y 30 de diciembre ${ }^{103}$, continuadas ese último día en el palacio de la Moncloa. A la media hora de iniciarse el día 31 de diciembre, el gobierno anunció el acuerdo ${ }^{104}$ : Navarra ahondaría en su vía foral provincial, salvo que el futuro órgano foral decisorio, que el Gobierno acordaría con la diputación en cumplimiento de la ley de 1841, optase por su incorporación al País Vasco y siempre que

\footnotetext{
96 "Los parlamentarios vascos, unidos... op. cit., p. 4.

97 “Acuerdos adoptados por la Asamblea de Parlamentarios”, en La Voz de España, 18 de diciembre de 1977, p. 4.

98 "Preautonómico: no modifican lo pactado", en La Gaceta del Norte (Bilbao), 18 de diciembre de 1977, pp. 1 y 8.

${ }^{99}$ Torres Murillo, José Luis, "UCD se pronuncia: Lo que decida la Constitución", en El Diario Vasco, 21 de diciembre de 1977 , p. 3.

${ }^{100}$ Clavero Arévalo, Manuel, España, desde el centralismo a las autonomías, Barcelona, Planeta, 1983, p. 50.

${ }^{101}$ Tamayo Salaberría, Virginia, La autonomía vasca contemporánea ... op . cit., p. 311.

102 "Moderado optimismo", en La Gaceta del Norte, 30 de diciembre de 1977, pp. 1 y 40.

103 Torres Murillo, José Luis, "El consenso entre los parlamentarios navarros dio luz verde a la preautonomía vasca", en El Diario Vasco, 31 de diciembre de 1977, p. 3.

104 “Autonomía para el País Vasco y Navarra”, en La Gaceta del Norte, 31 de diciembre de 1977, pp. 1 y 44.
} 
esa decisión fuera ratificada plebiscitariamente por los navarros. Así, quedó concretado en dos decretos-ley que aprobó el Consejo de Ministros del 30 de diciembre ${ }^{105}$. La UCD navarra había logrado salvaguardar sus postulados autonómicos, que permitirían al viejo reino transitar por su propia foralidad en la futura España descentralizada.

\section{Conclusiones}

La mutabilidad foral facilitó desde finales del siglo XIX diversas interpretaciones de la foralidad, permitiendo que se desarrollase en los diferentes marcos provincial y regional. Pese a que la segunda opción fue predominante en el siglo xx, llegando incólume a la transición democrática, la opción provincial mantenía sus partidarios. No solo desde las diputaciones, también en el seno de la UCD.

En esa formación política convivieron conceptualmente las interpretaciones tradicionalistas y constitucionalista de la foralidad, diferenciando los planteamientos de UCD en cada provincia. Mientras que la alavesa y la navarra apostaban por la vía provincial, la de Vizcaya lo hizo por el marco regional. Todas ellas defendieron la democratización en sus planteamientos descentralizadores, aunque atendiendo unos a un demos provincial y otros a uno regional. También la UCD guipuzcoana, que estratégicamente se escoró hacia lo provincial para buscar atraer el voto de la extinta GU, candidatura en la que se había refugiado el equipo directivo de la diputación de aquella provincia.

La contestada inclusión de la UCD de Álava en la APV permitió a Suárez contar con un caballo de Troya en el seno de la asamblea de parlamentarios, controlando a la organización unitaria vasca con el relevante peso electoral de su formación en la provincia meridional, mucho más significativo del logrado en los comicios en Vizcaya.

El maximalismo de la Diputación Foral de Navarra, con su planteamiento soberanista, forzó al gobierno Suárez a echarse en brazos de su partido en Navarra y respaldar su planteamiento autonómico uniprovincial, compartido por la diputación, pero que garantizaba la futura democratización de las instituciones forales. La última concesión de aquel gabinete fue aceptar que Navarra tendría que decidir en referéndum provincial si el organismo foral competente optaba por la integración de la provincia en el CGPV.

La quinta reunión plenaria de la APV supuso un fracaso con respecto a la anterior, donde la unanimidad fue absoluta. Las singularidades navarras habían recibido el apoyo de los centristas

\footnotetext{
${ }^{105}$ Real Decreto-Ley 1/1978, de 4 de enero, por el que se aprueba el régimen preautonómico para el País Vasco, en Boletín Oficial del Estado, del 6 de enero de 1978, núm. 5, pp. 326-327.

Real Decreto-Ley 2/1978, de 4 de enero por el que se regula el procedimiento para adoptar las decisiones en Navarra a que se refiere el Real Decreto-Ley 1/1978, en Boletín Oficial del Estado, del 6 de enero de 1978, núm. 5 , p. 327.
} 
alaveses, rompiendo el frente unido de la APV y quedando la UCD dividida por provincias, evidenciando que la constitución de la UCD del País Vasco era más nominal que real, aunque los planteamientos descentralizadores de todas ellas se inspiraban en la foralidad. 